\title{
Goal-oriented networks and capacity building for natural hazards - examples in the Dresden region
}

\author{
G. Hutter \\ Correspondence to: G. Hutter (g.hutter@ioer.de) \\ Received: 13 February 2013 - Published in Nat. Hazards Earth Syst. Sci. Discuss.: 10 April 2013 \\ Revised: 19 November 2013 - Accepted: 22 November 2013 - Published: 14 January 2014
}

Leibniz Institute of Ecological Urban and Regional Development (IOER), Dresden, Weberplatz 1, 01217 Dresden, Germany

\begin{abstract}
Networks and networking are important for building social capacities for natural hazards. However, up to now, it has been an open question which types of networks contribute to capacity building under certain circumstances. The paper focuses on the type of a goal-oriented network. The distinction between goal orientation and goal directedness is used to show the following: goal directedness of networks to build capacities for natural hazards involves intensive and continuous processes of "sensemaking" (Weick, 1995) to specify the network goal. This process of specifying an initial goal statement is important in small and large networks at the regional level. The governance form of a lead organization network facilitates goal specification. The paper illustrates these findings through evidence from two case studies conducted in the Dresden region in Germany.
\end{abstract}

\section{Introduction}

Social capacity building for natural hazards involves a broad agenda that covers, for instance, issues of knowledge creation and integration, strategy development, and financial resources, as well as participation and governance. Actors from various societal spheres are important for social capacity building (e.g., actors from local communities, the political sphere, administration, research organizations). Kuhlicke et al. (2011, p. 807) characterize social capacity building as a normative concept that aims to establish a long-term "learning process which is based on the cooperation and interaction of a variety of actors on different scales."

Networks, networking, and network capacities also have a place in an overall framework to analyze and improve capacity building for natural hazards (Kuhlicke et al., 2011, 2012).
Ample attention to networks, networking and network capacities helps to highlight the social aspect of "social capacity building". Networks as social structures and networking as actual processes connect people and organizations from diverse societal spheres. Because innovative solutions to solve problems of dealing with natural hazards often develop at the boundaries of diverse knowledge domains (e.g., Van de Ven, 2007), analyzing and improving networks may be of special importance to capitalize on the potential of social capacity building for natural hazards (e.g., Powell and Grodal, 2005). However, up to now, it has been an open question which types of networks (e.g., Diller, 2002; Powell and Grodal, 2005; Klijn, 2008; Raab and Kenis, 2009) contribute to social capacity building for natural hazards under certain circumstances.

This paper starts with the assumption that networks, networking, and network management are not inherently "good" and effective. The conditions under which certain types of networks contribute to social capacity building for natural hazards need to be specified and explained. To do this to a certain extent, the paper focuses on goal-oriented networks of organizations (Provan and Kenis, 2007, p. 231, use the term "goal-directed network"; see also Kilduff and Tsai, 2003). The paper adopts a network management perspective that pays ample attention to the structural features of networks and processes of network management (Klijn, 2008; see Geddes, 2008 and Sørensen and Torfing, 2005, 2007, 2009 , for a more macro-oriented perspective on networks). The paper argues that the specifics of goal orientation of network actors are crucial variables in understanding and explaining the effectiveness of networks and their contribution to capacity building for natural hazards (Vlaar et al., 2006; Provan and Kenis, 2007). 
Networks are important for connecting actors from diverse societal spheres. Given that actors are significantly influenced by conditions in these spheres (e.g., formal institutional constraints, informal ways of solving problems), it is necessary to demonstrate that network actors actually work together in the direction of a goal at the network level (Huxham and Vangen, 2005). Goal-orientation of networks does not necessarily imply and lead to the goal directedness of decisions and actions of network members. Goal directedness of decisions and actions is a specific achievement. Against this background, the paper asks the following question: how do network actors create goal directedness in networks that aim to build social capacities for natural hazards?

The paper explores this question based on two case studies about goal-oriented networks in the Dresden region in Germany (Hutter et al., 2011; Hutter, 2012; Hutter and Bohnefeld, 2013). Both networks deal with the challenge of adapting to climate change in cities and regions. Both address issues of dealing with natural hazards in the context of climate change adaptation. The author of the paper was intensively involved in establishing the two networks and in managing them, especially with regard to issues of long-term planning. The paper is an attempt to reflect on these experiences and to propose some generalizations about the cases (Yin, 2009). In the future, the findings of the paper may feed into more theory-oriented approaches to network development in the context of social capacity building for natural hazards (based, for instance, on the work of Borgatti and colleagues - Jones et al., 1997; Borgatti and Foster, 2003; Borgatti and Halgin, 2011).

The following two sections present the concepts to provide a framework for the case studies (Yin, 2009): Sect. 2 is about the concept of a "goal-oriented network". Section 3 seeks to clarify the relations between goal-oriented networks as networking episodes and continuous processes of social capacity building. Section 4 introduces the two examples in the Dresden region as case studies. Section 5 shows two conclusions.

\section{Goal-oriented networks}

In its most general form, the term "network" refers to a set of nodes and a set of ties that connect the nodes to some extent (in the social sciences, nodes are called network actors). This general notion is used in various scientific disciplines and policy contexts. The paper mainly refers to the literature about network relations between organizations (inter-organizational network, see Borgatti and Foster, 2003; Provan and Kenis, 2007; Klijn, 2008; Raab and Kenis, 2009). Hence, the sociological literature about social networks on the one hand and research findings about networks in organizations on the other are in the background of analysis (see Van Wijk et al., 2003 for a review).
It is important to distinguish between different types of networks (Diller, 2002; Kilduff and Tsai, 2003; Powell and Grodal, 2005; Wiechmann, 2008; Raab and Kenis, 2009). This paper uses the concept of a goal-oriented network to address issues of network management in the context of social capacity building for natural hazards. This concept has the following core features:

- Goal orientation at the network level: A network of organizations declares to realize a goal that is communicated to external organizations as the desired joint output of network actors in the future. The rationale for establishing a network is based on the belief that new ties between organizations are necessary to realize the goal. The paper focuses on a type of network with an initial goal statement that needs some specification to be instructive for interpretations, decisions and actions of network actors. Goal-oriented networks refer to multiple levels of social relations (the group, the organization, the network, see Knight, 2002; Huxham and Vangen, 2005; Raab and Kenis, 2009).

- Collaboration between network actors: In general, networks can combine collaborative and competitive relations (Powell, 1990). A goal-oriented network in particular is based on the belief that collaboration between network actors will lead to the realization of the network goal (Huxham and Vangen, 2005; Ansell and Gash, 2007).

- Formal and informal processes of network management: A goal-oriented network shows some formalization of interaction between the network actors (Ansell and Gash, 2007). The term "formalization" refers to both processes of agreeing on and codifying formal structures, procedures, and so forth, and the output of this process in terms of network-specific documents (Vlaar et al., 2006). Of course, informal processes of communication are also relevant for goal-oriented networks (Ring and Van de Ven, 1994).

Provan and Kenis (2007) speak of "goal-directed networks". We prefer the term "goal-oriented" because it is the main question of this paper how (and to what extent) networks of organizations develop goal directedness in the context of social capacity building for natural hazards.

Goal-oriented networks are characterized by a complex set of structural features, network processes, and outputs. There is no "grand theory" that covers all these aspects of goaloriented networks (e.g., Provan and Sydow, 2008). We argue that goal orientation in the context of capacity building for natural hazards is significantly influenced by four kinds of variables: (1) processes of making sense of the network purpose to advance from goal orientation to goal directedness, (2) network size, (3) composition of network actors, and (4) network governance form. 
Table 1. Comparing goal orientation and goal directedness of whole networks.

\begin{tabular}{ll}
\hline Goal orientation & Goal directedness \\
\hline $\begin{array}{l}\text { Goal orientation is a core feature of a whole network; abstract } \\
\text { goal statements are mainly formal }\end{array}$ & $\begin{array}{l}\text { Goal directedness is a variable of a whole network; specific } \\
\text { statements may be formal and informal }\end{array}$ \\
$\begin{array}{l}\text { Goal statements help to justify the existence of the network with } \\
\text { regard to the stakes of external actors }\end{array}$ & $\begin{array}{l}\text { Specific goal statements help to coordinate and motivate actions } \\
\text { of network actors }\end{array}$ \\
$\begin{array}{l}\text { Goal orientation is important for achieving legitimacy of a whole } \\
\text { network }\end{array}$ & $\begin{array}{l}\text { Goal directedness is important for achieving effectiveness of a } \\
\text { whole network }\end{array}$ \\
\hline
\end{tabular}

\subsection{Goal directedness}

The distinction between goal orientation and goal directedness is crucial to understanding this paper (see Table 1). Goal orientation means that network actors are aware of being involved in a network that declares to realize a goal at the level of a whole network. Goal orientation is, as mentioned above, the rationale for establishing the network. However, this does not necessarily imply that the "official" goal statement is actually of high relevance for interpretations, decisions and actions of network actors. A network goal statement may only be the "façade" of a network to justify its existence in the face of powerful external actors, like organizations that provide the network with resources. Behind this "façade", network actors may follow their own agendas that are only loosely coupled to the network goal, if at all (Meyer and Rowan, 1977; Scott, 2008).

Goal orientation is a core network feature, whereas goal directedness may vary with regard to, among others, the willingness, capabilities, and resources of actors to make sense of a network goal. Goal directedness means that an initial network goal statement is the content of intensive processes of interpretations, decisions and actions of network actors. It encompasses at least the following two processes:

- Specification: The paper considers networks with initial goal statements that are quite abstract and/or ambiguous. Goal directedness is a process that specifies the content of the goal statement and how network actors interpret goal statements. "Goal-directed network trajectories develop around specific goals that members share." (Kilduff and Tsai, 2003, p. 89, italics added). Healey (2009, p. 449) uses the similar, but more ambiguous term of "framing selectively" to argue that goal directedness "involves a selective focus. It offers a way through the morass of issues, ideas, claims and arguments to identify one or more concepts, images and/or principles which are both meaningful and give direction."

- Implementation: Network actors interested in goal directedness are also concerned with delivering in a more formal way what the network promised to deliver at the outset of establishing the network. Implementation means demonstrating through documented evidence that an initial goal statement has actually been realized in terms of specific network outputs, whatever the content and (argumentative) quality of these products may be.

We assume that making sense of the network goal through some specification and implementation is necessary for network effectiveness (Provan and Kenis, 2007). This assumption is in line with an interpretative approach to understanding and explaining networks and organizations (Aldrich and Ruef, 2006, p. 43-46). An interpretative approach sees goal orientation and goal directedness, especially in the case of networks with high or modest heterogeneity (Eden and Huxham, 2001; Huxham and Vangen, 2005), as unstable social processes "constantly at risk of dissolution" (Aldrich and Ruef, 2006, p. 45). Network actors face the challenge of making sense of the network goal (Weick, 1995; Vlaar et al., 2006). This social process is influenced, among others, by the network size, the composition of the actors, and especially the network governance form.

\subsection{Network size}

The term "network size" may refer to various features of goal-oriented networks. A network may grow because of new ties between network members that were previously unconnected. Size is measured by counting the ties between network actors. An alternative understanding is that a network may increase its size due to the entry of new network members. Size is measured by counting the network actors ("number of nodes"). This paper refers to the latter for understanding network size.

It is assumed that network size is influenced by, among other factors, funding conditions for the establishment of goal-oriented networks. Network size is also influenced by the willingness of actors to participate in a network based on voluntary, perhaps more informal resource contributions. Furthermore, network research has shown that existing network relations significantly influence the emergence of new networks (Gulati et al., 2002). 
Why is network size important for network management? Firstly, network size can have an influence on the degree of formalization of interactions between network members. Large networks are more involved in formalization than small networks. However, there are complex causal relations between network size and management that will be explored in the two case studies. Secondly, network size influences what network actors and external actors expect from a network as appropriate output. To put it simply: large networks may evoke high expectations of the contribution of a network to social capacity building. However, high expectations may also emerge due to the high level of trust between network actors and/or the trustworthiness and prominence of the network from the viewpoint of external actors. In contrast, actors in small networks may have the impression that they are forced to be pragmatic about what is expected from the network right from the outset of networking. To generalize this reasoning: it is important to consider the starting conditions of a goal-oriented network (see Ansell and Gash, 2007 and Sect. 3 on goal-oriented networks as networking episodes with a start and a finish).

\subsection{Heterogeneity: composition of actors}

The meanings of the term "heterogeneity" may also vary. Here, the term refers to differences between network actors that are strongly influenced by formal and informal institutional conditions of these actors. The term "institution" covers not only regulatory institutional constraints, but also normative and cognitive-cultural institutions that are important for understanding why an actor interprets, decides and acts like he or she does (Scott, 2008).

The meaning of the term "network heterogeneity" is much broader than the heterogeneity of actors. Network heterogeneity depends on complex conditions (see Ansell and Gash, 2007), for instance, the history of network relations and processes of agenda setting in regions (Wiechmann, 2008).

Sandström and Carlsson (2008, Carlsson and Sandström, 2008) argue that networks with high heterogeneity are necessary, but not sufficient conditions for finding innovative solutions in the context of natural resource management. Network actors with heterogeneous institutional backgrounds provide an equally heterogeneous pool of information, knowledge and referrals that are important for finding innovative solutions. Vlaar et al. (2006) argue that goaloriented networks with high heterogeneity require intensive and complex processes of "sensemaking" (Weick, 1995) to capitalize on the potential of heterogeneous networks to find innovative solutions (Van Wijk et al., 2003). These authors agree that high heterogeneity can be both a blessing and a curse for goal-oriented networks (Benz and Fuerst, 2002). High heterogeneity may be a blessing if network actors find a way to develop a common understanding as a basis for jointly specifying and implementing the network goal. High heterogeneity may be a curse if it prevents the network actors from developing a focused common agenda that is specific enough to direct interactions.

\subsection{Network governance form}

A network can be understood as a form of governance that is compared with markets and hierarchies as alternative governance arrangements (see the seminal article by Powell, 1990). This paper takes a closer look at goal-oriented networks and how they are managed based on a specific "form of network governance" (Provan and Kenis, 2007, p. 233; Raab and Kenis, 2009, p. 207, use the term "governance forms of whole networks"). The term refers to network structures that shape, firstly, who the main decision makers are with regard to goal orientation at the network level and that shape, secondly, how these decisions are made. Provan and Kenis (2007) distinguish between three forms of network governance:

- A lead organization network is a goal-oriented network in which one organization shapes the interpretations and decisions about the goal of the network and about the ways to realize it. Kilduff and Tsai (2003, p. 87-110) assume that goal-oriented networks are usually led by one powerful organization with the internal and external legitimacy to steer network development. In this paper, we consider further network governance forms.

- A network administrative organization is a network that is characterized by the establishment of a new network-specific administrative unit responsible for network management. All network actors have strong ties with the administrative unit. Often, they contribute to establishing the financial basis of the unit.

- A network with shared governance is a network in which all network actors, in principle, have the duty and possibility to shape fundamental decisions about the goal of the network as well as ways of goal specification and implementation (Geddes, 2008 uses the term "partnerships"). Provan and Kenis (2007) argue that shared governance is effective in small networks that require only limited professional network management competencies.

The governance form of a goal-oriented network may be due to deliberate decisions of powerful actors at the outset of establishing the network. The governance form may also develop in a more evolutionary way without a "mastermind" choosing the form of the network. The governance form of a goal-oriented network is difficult to see and control because the term refers to the whole network and not to the perceptions of single network actors. This may hold especially for large networks. However, we follow Provan and 
Table 2. Three levels of attention to analyze goal-oriented networks from a network management perspective (source: inspired by Weick and Quinn, 1999; Healey, 2007; Jones and Liechtenstein, 2008; Raab and Kenis, 2009).
Level No. 1
Episodic networking
Specific episode of networking (e.g., goal-oriented networks as project networks; see case studies about
Level No. 2
KLIMAfit and REGKLAM)
Continuous networking
Continuous processes of networking in the context of existing multiple networks that are partly con- nected (e.g., regional "landscape" of governance networks)
Level No. 3
Basis of networking
Basic assumptions and values of networking and networks (e.g., assumptions about time and temporal- ity of project networks)

Kenis (2007), who argue that the governance form of a network is crucial for goal specification and implementation and therefore for its effectiveness.

\section{Goal-oriented networks and capacity building}

Networks and networking are, as mentioned in the introduction, important for social capacity building for natural hazards (Kuhlicke et al., 2011). However, the relations between networks and capacity building are complex and uncertain and may show desired as well as undesired consequences. Furthermore, there are many different ways of classifying networks to understand the relations between networks and capacity building. This raises the question of how the relations between goal-oriented networks and capacity building are conceptualized in this paper: the relations between networks and capacity building are conceptualized from a network management perspective based on the distinction between episodic and continuous processes (Weick and Quinn, 1999). Table 2 summarizes this conceptualization.

The following highlights three implications of this conceptualization with regard to the two case studies about KLIMAfit and REGKLAM (see below):

- Episodic networking: Networking sometimes refers to specific projects ("project network", Windeler and Sydow, 2001). Partners work together to accomplish a specific task with fixed time limits ("project duration") and resource constraints. Networking has a beginning and an end due to formalized agreements and obligations (Vlaar et al., 2006; Ansell and Gash, 2007). Both case studies refer to such project networks and processes of episodic networking.

- Continuous networking: Project networks often emerge in the context of existing social relationships (Gulati et al., 2002) and seek to influence these relationships during project realization and by delivering the project network output (Healey, 2007). Both project networks in the case studies were established to make contributions to continuous decision-making processes in the Dresden region. Actors that are involved in KLIMA fit and REGKLAM continue networking after these two project networks have accomplished their tasks (e.g., by using project network results in formal processes of updating the regional plan for the Dresden region). The interface of episodic and continuous networking may be organized by actors that participate in multiple networks. Organizing this interface can be a difficult task, for instance, because formal processes of decision making related to continuous networking are shaped through complex power relations, divergent interests as well as attempts to ensure the "democratic anchorage" of networks (e.g., Benz and Fuerst, 2002; Sørensen and Torfing, 2009).

- Basis of networking: Processes of networking reproduce basic assumptions and values that refer to "deep" societal structures and institutions (e.g., Weick, 1995; Scott, 2008; Raab and Kenis, 2009). For instance, basic assumptions about time and temporality are important for analyzing the contribution of project networks to capacity building from a network management perspective (Jones and Liechtenstein, 2008). Project networks are based on assumptions about time as being homogeneous, divisible, linear, measurable, objective, and abstract (McGrath and Rotchford, 1983). Basic assumptions and values reduce the complexity of "possible worlds" to a "realistic" set of networking options that network actors are able to handle. However, in the long run, nearly everything of networking may change, even assumptions about time and temporality (Orlikowski and Yates, 2002).

This conceptualization of three levels of networking does not refer to levels of "reality" or "levels of network governance in the real world" (Healey, 2007). All three levels are in play during a specific episode of networking. Table 2 is a heuristic device to clarify the focus of attention. Network actors as well as researchers may focus on a specific level of networking (e.g., the level of a specific networking episode) against the background of the other levels; they may try to consider all three levels of networking ("multi-level analysis") to answer questions of capacity building for natural hazards. 
The literature shows alternative ways of conceptualizing the relations between networks and capacity building. Some are mainly interested in the scope of change in the context of climate change adaptation (e.g., Pelling, 2011 considers resilience, transition, and transformation). The literature also shows a focus on a specific type of event to analyze capacity building (e.g., Comfort et al., 2010 on "Designing resilience: preparing for extreme events"). Others analyze network capacities within an overall framework of social capacity building for natural hazards. They distinguish between an interventionist and a participatory approach to capacity building (Kuhlicke et al., 2011).

The conceptualization summarized in Table 2 is different to the existing literature because of its emphasis on the dimensions of "time" and "temporality" of networking. Specific episodes and continuous processes of networking as well as basic assumptions about networks can only be identified by explicating the dimension of time. This emphasis on time and temporality is consistent with an understanding of social capacity building as a "normative concept that describes the process of (re-) discovering, enhancing and developing. .. resources and abilities. It is thus a long-term, iterative and mutual learning process which is based on the cooperation and interaction of a variety of actors on different scales." (Kuhlicke et al., 2011, p. 807, italics added). Capacity building in this understanding encompasses all three levels of attention to processes of networking.

The focus in the case studies is on the first level of attention to networking. However, the studies are also used to understand the implications of specific networking episodes in the context of continuous processes at the regional level of capacity building for natural hazards.

\section{Two examples of goal-oriented networks and capacity building for natural hazards in the Dresden region}

In the Dresden region, it is possible to observe various goaloriented networks that seek to make a contribution to social capacity building for natural hazards (see Fig. 1). The following focuses on two project networks (full names of the networks and the supporting institutions are given in the section on acknowledgements): firstly, the KLIMAfit network was a small network led by regional planners and supported by the German Federal Government. The network deals with issues of adapting to the impacts of climate change at regional level, especially with regard to flood risk management and torrential rain resulting in increased soil erosion. Secondly, there is the REGKLAM network, a large network also funded by the German Federal Government. It was the goal of REGKLAM to formulate a comprehensive program for the Dresden region to adapt to climate change, including issues of dealing with natural hazards.
The author was, as mentioned in the introduction, involved in establishing both networks. In the case of REGKLAM he was responsible for organizing the process of program formulation based on concepts from planning research (e.g., Healey, 2009; Wiechmann, 2008; Hutter and Wiechmann, 2010). In the case of KLIMAfit, he was responsible for supporting the regional planners in implementing the network goal (Hutter, 2012).

Why are these two goal-oriented networks chosen to analyze relations between networking and capacity building for natural hazards? Firstly, both the KLIMAfit and REGKLAM project networks provide documents with sufficient statements about the goal orientation of the network. Secondly, the involvement of the author in establishing and managing the two networks allows insights about complex variables such as goal directedness, heterogeneity, and governance form that are difficult to obtain as an outsider of a project network (Yin, 2009). Thirdly, the actors of both project networks have several years of experience and expertise in dealing with natural hazards (e.g., knowledge capacities with regard to river floods in the Dresden region, Kuhlicke et al., 2011, 2012). Relations between networking episodes and capacity building may be easier to analyze, if network actors can "start" working together on the basis of some common knowledge about natural hazards and their consequences ("starting conditions", Ansell and Gash, 2007).

KLIMAfit was a project network with a formally defined duration from July 2009 until April 2013. New networks emerge in the context of existing networks (Gulati et al., 2002). KLIMAfit emerged in the context of the REGKLAM project network, which was established in July 2008 and will end in December 2013. However, the following starts with the case study about KLIMAfit because the structural features of this network facilitate an understanding of how network actors create goal directedness to build capacities for natural hazards. The section compares the two cases of goaloriented networks to highlight some similarities and differences (Dougherty, 2002; Yin, 2009).

\subsection{KLIMAfit case study}

The emergence of new networks is an iterative and dynamic process. Network actors try to make sense of relations between possible desired consequences of networking ("goals") and the means and the resources to realize these consequences. This assumption about network emergence helps one to understand why initial network goal statements may be rather abstract and why they need specification. Network actors assume only after several rounds of making sense of the (possible) network goal that others are reliable and trustworthy. Until then, network actors prefer to commit only to abstract goal statements that leave enough leeway for interpretation while network relations develop 


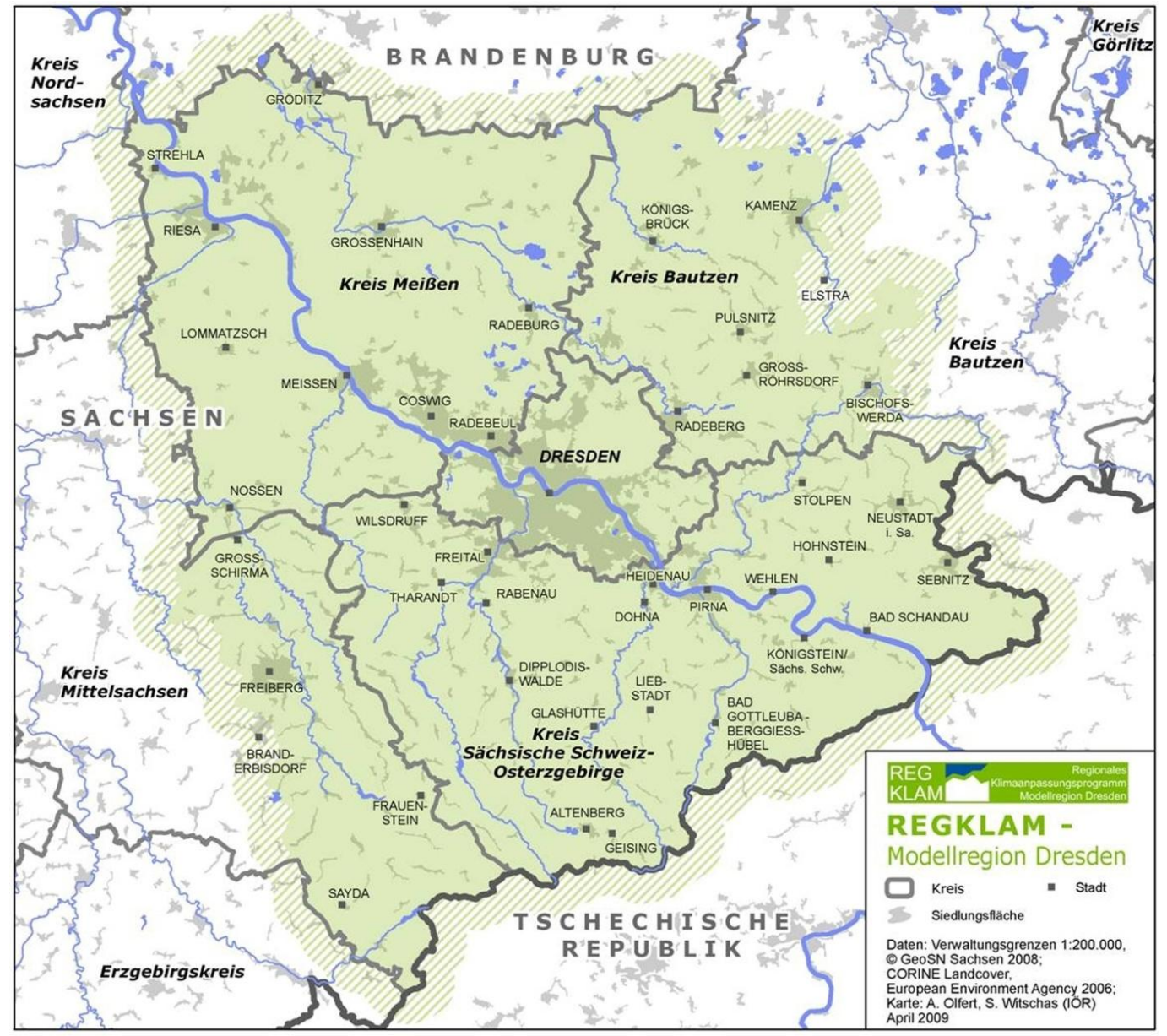

Fig. 1. The Dresden region as defined in the REGKLAM project network. The region is an approximation of the planning region relevant to the KLIMAfit project network (source: Roessler et al., 2013, p. 127).

further and transaction costs become clearer (Ring and Van de Ven, 1994; Vlaar et al., 2006).

In line with this understanding of network emergence, KLIMAfit was established by representatives from the regional planning office based on communication with potential network partners in the context of meetings of the REGKLAM network. The possibility of applying for funding organized by the German Federal Government within a program about innovative solutions for climate change adaptation and spatial planning triggered this process of communication between the potential network partners of KLIMAfit. Regional planners were motivated to apply as "lead partner" for this funding because REGKLAM does not focus on the specific issues of statutory regional planning for climate change adaptation. Regional planners claimed "ownership" of KLIMAfit right from the beginning and were willing to make significant resource commitments, also to comply with the many detailed procedures and requirements defined by the Federal Government.

\subsubsection{From goal orientation to goal directedness}

KLIMAfit was characterized by an intensive process of goal specification that can be divided into three phases:

1. KLIMAfit started with a rather abstract overall goal statement to justify networking. The network declared to formulate a strategy that (1) leads to the "implementation" of existing regional planning statements for climate change adaptation (as mainly defined in the existing and legally approved regional plan) and that (2) takes non-statutory planning, especially regional management, more intensively into account. This goal statement corresponds with the well-known argument of planners and planning researchers that statutory planning is not enough to consider long-term challenges with high uncertainty like climate change and that applying a complex portfolio of instruments based on intensive collaboration and networking is needed (e.g., Greiving, 2010; Klemme, 2011). Other parts of the application for funding were much more detailed 
with regard to climate change adaptation and the conditions of the Dresden region.

2. In March 2011, KLIMAfit provided some interim results defined as products: Product No. 1 included detailed empirical results, for instance, about climate change at regional and sub-regional level to consider the interests of regional managers as well as survey results about the relevance of existing regional planning statements for local planning. Product No. 2 gave an overview of recommendations for regional planning and regional management in the Dresden region to consider climate change adaptation more systematically in future planning processes. These recommendations focused on a relatively broad agenda of planning issues (e.g., aforestration at specific locations within the region, issues of soil erosion and flood risk management, topics of regional management in rural areas, implementation issues at multiple levels of strategy making).

3. From April 2011 to April 2013, the German Federal Government continued to support KLIMAfit based on a more selective choice of planning issues. Regional planners and the Federal Government agreed to focus on two issues: firstly, flood risk management to enhance the influence of regional planning on the building stock, especially with regard to extreme flood events; secondly, dealing with soil erosion due to torrential rain through a more selective process of prioritizing the most vulnerable areas in the Dresden region. Planners expected that this would increase the likelihood of implementing some measures for reducing soil erosion.

In this process of goal specification, the regional plan served as a reference point in network communication, either to specify the content of further processes of statutory planning or to justify activities that are seen as complementary to statutory planning. The following shows the structural conditions of this process of goal specification.

\subsubsection{Network size}

Compared to the REGKLAM network, KLIMAfit was a relatively small project network. The regional planning office was the lead partner, supported by the "Leibniz Institute of Ecological Urban and Regional Development (IOER)" research organization in Dresden. Representatives of two and then three regional management offices acting on behalf of municipalities in rural areas in the Dresden region were also actors of the project network. Further network actors were the "Saxony State Interior Ministry (SMI)" represented by an official responsible for spatial planning and a state agency that supports the "Saxony State Ministry for Environment and Agriculture (SMUL)" with regard to knowledge about climate change and climate change adaptation. Retrospectively, it is possible to observe strong ties between these seven organizations as network partners. Weak ties developed during project network implementation to include actors relevant for issues of, for instance, soil erosion, flood risk management, and regional management on a temporary basis in the network (e.g., representatives of municipalities, authorities responsible for forestry in the Dresden region, the "Technische Universität Dresden (TUD)").

Due to the perceived contrast in network size between REGKLAM and KLIMAfit, network actors agreed at an early stage of working together that the expected network output would be pragmatically defined and much more limited than in the case of REGKLAM. However, network actors communicated this expectation in a more informal way in the first and second phases of goal specification. This may be due partly to the context of funding and the overall program of the German Federal Government on climate change and spatial planning. Federal government as well as supporting research organizations and consulting firms raised a broad agenda of planning issues and related questions that made early "open" communication about a "selective focus" of KLIMAfit somehow difficult. In a market context, it is probably easier to agree on a "niche" at an early stage of networking when the resource basis is as limited as in the case of KLIMAfit (e.g., less than EUR 100000 funding by the Federal Government for the whole project duration, Hutter, 2012).

\subsubsection{Network governance form}

High reliability characterized the process of working together in KLIMAfit in all phases of goal specification. The relatively high degree of formalization (relative to the network size) facilitated intensive communication between the network actors and effective reporting mechanisms. However, it would be misleading to understand KLIMAfit as a network with the governance form of shared governance. The regional planning office was the lead organization from the outset of project network development. Network actors never questioned the lead role of the regional planning office (high internal legitimacy). The planning office controlled communication with the German Federal Government and presented the main findings of the network (high external legitimacy). Regional planners also defined the main parameters of the process of goal specification (e.g., the regional plan and planning procedures as reference points for specifying the network goal). However, within this framework set by the planning office, network actors had significant leeway for discussion and for working out the details of advancing regional planning and regional management. As mentioned in the introduction to this case study, the decision to establish a network as a lead organization network was to some extent deliberate and shaped by the process of applying for funding by the Federal Government. Strong leadership based on the network governance form of a lead organization network 
facilitated goal specification in KLIMAfit. We propose that the governance form is more important for a successful process of goal specification than the size or the heterogeneity of the network (Kilduff and Tsai, 2003).

\subsubsection{Heterogeneity}

A further contributing structural factor was the modest degree of heterogeneity of actors. The group of repeatedly interacting individuals that represented the seven KLIMAfit network actors shared a similar understanding of the strengths and weaknesses of regional planning and regional management. To put it simply, KLIMAfit was a small network of spatial planners and planning researchers. Actors with a moderate or high "cognitive distance" (Nooteboom, 2008 , p. 616) to planning participated mainly in events organized by the network (e.g., representatives of land owners, farmers, forest management, citizens). Network actors focused on the question how to structure and interpret the high complexity and heterogeneity of contents that are relevant to building capacities for natural hazards in the context of climate change (e.g., assessing and dealing with uncertainty of climate change variables, analyzing land use changes with a complex spectrum of evaluation criteria, discussing different approaches to understand and analyze flood risk related to extreme flood events).

\subsubsection{Case study summary}

KLIMAfit was a small project network led by the regional planning office in the Dresden region. Network actors created goal directedness through an intensive process of goal specification that lasted for more than three years. Strong leadership shaped this process. Network actors that were connected through strong ties were mainly planners or planning researchers. Joint attention of the network actors to the regional plan and statutory planning made it possible to find "a way through the morass of issues, ideas, claims and arguments" (Healey, 2009, p. 449) that are relevant for climate change adaptation in regions. It is likely that some project network results will feed into the process of updating the existing regional plan (due in four years after the publication of the new development plan at the level of the Free State of Saxony in August 2013).

It is too early to analyze the overall influence of KLIMAfit on social capacity building for natural hazards in the Dresden region. However, during project network development it became clear that the regional planning office is able to use the project network for effective preparation of an update of the regional plan, including the "hot topic" of flood risk management in the Dresden region. This effective preparation is partly due to the intensive process of goal specification. In contrast, the following case study about the REGKLAM network shows that network actors may have some difficulties in achieving goal specification to discuss priorities of capacity building in the context of climate change adaptation.

\subsection{REGKLAM case study}

The REGKLAM project network is exceptional in at least two aspects: firstly, the German Federal Government supports the network through a grant of approximately EUR 11 million. Mainly research organizations in the Dresden region use this grant to finance their activities to establish and implement REGKLAM. Some organizations from practice have a share in this large budget (e.g., the City of Dresden and the state agency that is responsible for supporting the Free State of Saxony with regard to environmental and agricultural policy as well as geology, the "Sächsisches Landesamt für Umwelt, Landwirtschaft und Geologie (LfULG)"). Secondly, the Federal Government has supported REGKLAM from July 2008 until December 2013, a relatively long project duration compared to many other state-financed research projects. It is important to know that researchers in the Dresden region initiated the REGKLAM project network to organize the application for funding through the Federal Government (for instance, researchers from the IOER, the "Technische Universität Dresden" (TUD), and the "Technische Universität Bergakademie Freiberg (TU BAF)"). REGKLAM emerged in the context of existing dense network relations between various researchers from these organizations and based on some joint project experiences. However, the actor composition of the whole REGKLAM network, the planned project duration, the available budget as well as the ambitious aim to develop a climate change adaptation program for the Dresden region were new to all network actors.

\subsubsection{Goal orientation and goal directedness}

In its application for funding, the REGKLAM project network declared to realize three goals: firstly, the network promised to formulate an "Integrated Regional Climate Change Adaptation Program" to make a significant contribution to the long-term development of the Dresden region. Secondly, the network promised to implement some projects and measures for climate change adaptation related to the program. Thirdly, the network declared to consolidate existing network relations in the Dresden region. The following focuses on the first goal statement of REGKLAM. It mainly considers the contents of the process of specifying the network goal in a summarized form as agenda building to formulate the climate change adaptation program. As with KLIMAfit, it is possible to distinguish three phases of agenda building in the case of REGKLAM:

1. REGKLAM started, on the one hand, with a project agenda that covered the specific topics of individual "work packages" as defined by researchers during the process of applying for funding at national level. The 
spectrum of these topics covered projections of regional climate change and socio-economic changes as well as impact assessments for settlements and open spaces, agriculture and forestry, and natural and technological water systems. On the other hand, a working group of high-ranking practitioners and researchers started to define the agenda of the climate change adaptation program (the "Integrated Regional Climate Change Adaptation Program" working group). The majority of the group members showed some affinity for planning and strategy development (e.g., regional planning, city planning, and strategies of business organizations). The group considered the specific topics of the scientific work packages as well as further topics that were judged to be important for climate change adaptation in the Dresden region (e.g., flood risk management, health issues, nature conservation). As a consequence of this complex process of agenda building, the working group structured the contents of the climate change adaptation program into "strategic themes". The agenda now covers issues of adapting the building stock, settlement structures and open spaces as well as issues of water management, agriculture, forestry, economic development, and nature conservation. Natural hazards are considered within these themes (e.g., issues of soil erosion due partly to torrential rain are considered in the strategic themes of "agriculture" and "nature conservation").

2. The second phase was characterized by intensive processes of formalization and implementation, but not by equally intensive processes of specification as a basis for setting priorities of climate change adaptation. Formalization means that network actors agreed on the codification of the contents of strategic themes (challenges of climate change adaptation, theme-specific Leitbilder, aims and measures). They also agreed on procedures and organizational arrangements as well as flexible resource commitments to bring the complex and detailed contents together in one document - the long version of the climate change adaptation program. The final version of the program shows approximately 330 pages.

3. The REGKLAM project network includes various research organizations and practitioners from the Dresden region (see below). However, politicians, citizens, and representatives of organizations belonging to the "civil society" are mainly included on a limited temporary basis (e.g., a workshop, a meeting). Network actors were aware of this exclusive character of REGKLAM (Hutter and Bohnefeld, 2013). Furthermore, network actors agreed that a program document with more than 300 pages would be suitable only for experts and officials already involved in more "technical" aspects of climate change adaptation. It also became apparent that the draft of the program lacks a "selective focus" (Healey, 2009, p. 449). The primary representatives of the network actors of REGKLAM decided to formulate a short version of the climate change adaptation program. The short version was presented at a large workshop located at the parliament of the Free State of Saxony in Dresden in November 2012. Politicians from various political parties participated in this workshop.

In summation, the process of goal specification in REGKLAM is relatively limited (compared to KLIMAfit). The agenda of the program was broad at the beginning and will remain broad until the end of REGKLAM. The long and the short versions of the climate change adaptation program cover a wide spectrum of issues that are, in principle, relevant for long-term development in the Dresden region. However, it is difficult to discuss and identify priorities of adaptation based on these planning outputs. In the case of REGKLAM, moving from goal orientation to goal directedness primarily unfolded as processes of formalizing and implementing the network goal. In contrast, specification in the sense of creating "specific goals that members share" (Kilduff and Tsai, 2003 , p. 89) or in the sense of creating a "selective focus" was more in the background or absent in REGKLAM (Hutter and Bohnefeld, 2013). The following tries to explain this by referring to the three structural variables of size, composition, and network governance form.

\subsubsection{Network size}

The grant by the German Federal Government is an important indicator that REGKLAM is a large project network. As mentioned above, research organizations received most of the grant to finance research activities and coordinating activities to realize the three main goals of REGKLAM. However, it would be misleading to understand REGKLAM only as a research network. Firstly, as mentioned above, some organizations from practice received parts of the grant. Secondly, various organizations from the administrative and intermediary as well as the private sphere participated in the project network development of REGKLAM (e.g., spatial planners from different levels, representatives from ministries and state agencies, from the chamber of commerce in Dresden). The three main goals of REGKLAM provided the rationale for the intensive inclusion of practitioners in the decisionmaking organizational units of REGKLAM. Approximately 100 organizations were included in REGKLAM - with various degrees of intensity and through various ways of organizing the inclusion (Hutter and Bohnefeld, 2013). With regard to the observed limited goal specification of REGKLAM, the paper proposes that large network size makes specification difficult through its potential influence on the degree of heterogeneity. 


\subsubsection{Heterogeneity}

Two features of REGKLAM are salient with regard to the heterogeneity of actors. Firstly, the project network includes some types of actors only on a limited temporary basis (e.g., politicians) and excludes some types of actors (e.g., citizens). Secondly, the network includes some types of organizations intensively and in a highly differentiated way according to "strategic themes" that is difficult to understand for outsiders (e.g., research organizations with researchers from various scientific disciplines, various departments of the local administration of the City of Dresden, spatial planning at regional and state level, state agencies, representatives of the economic sector). The composition of network actors shows a bias towards organizations with "strong views" on how to analyze the challenges, aims, and measures of climate change adaptation, but only "weak views" on how to make legitimate decisions to get adaptation focused on only a few issues of a political agenda.

Symptoms of high heterogeneity of actors within a selective composition of network members can be seen in discussions about "integration". Different researchers interpreted this term very differently (e.g., integration as the rationale of applying a specific method, integration of cause-effect relations versus integration of aims and measures in different strategic themes of the program). Researchers and practitioners "naturally" also followed different understandings of what integration means in REGKLAM and why it is important (see details in Hutter and Bohnefeld, 2013). Network size and the high heterogeneity of actors jointly made an agreement between the REGKLAM actors on the process of content specification in terms of a focused agenda difficult.

\subsubsection{Network governance form}

Furthermore, REGKLAM can be understood as a network with a hybrid network governance form and multiple identities. Firstly, it is important to consider that all formal network actors (the seven organizations applying for funding, six research organizations and the City of Dresden) were autonomous with regard to the formal management and reporting to the Federal Government as funding organization. It is formally correct to say that REGKLAM was coordinated, not led, by the IOER. Therefore, the form of a lead organization form does not apply. The form of shared governance is only applicable to parts of REGKLAM, not to the whole network due to its size. Furthermore, REGKLAM did not establish a new administrative unit for the project duration. Therefore, we conclude that REGKLAM is characterized by a hybrid network governance form with elements that need further description and explanation.

Secondly, REGKLAM is a project network that connects researchers in and between specific work packages (network of researchers), and it is also a governance network (Sørensen and Torfing, 2005, 2007, 2009) with the goal of serving the "public purpose" by formulating a climate change adaptation program for the Dresden region. Multiple identities and related evaluation criteria are important for REGKLAM (Provan and Sydow, 2008).

The case study about KLIMAfit points to the argument that strong leadership based on a lead organization network could have facilitated goal specification as a contributing process to creating goal directedness. However, directedness in REGKLAM was still realized to some extent due to resourceintensive processes of formalization and implementation.

\subsubsection{Case study summary}

REGKLAM is a large project network coordinated by the "Leibniz Institute of Ecological Urban and Regional Development (IOER)" research organization in Dresden. Network actors created the limited goal directedness of the network through intensive processes of formalizing the "Integrated Regional Climate Change Adaptation Program" network output. However, the final documents of the program show no "selective focus" to enhance the goal directedness of the network. The agenda of the program covers a complex set of issues with only some considerations of interdependencies between the issues (e.g., conflicts between measures of agricultural policy and measures to reduce soil erosion due partly to torrential rain). The limited extent of goal directedness corresponds to the hybrid form of network governance and the high degree of heterogeneity of the network actors that is due partly to the large size of the network. Under these circumstances, goal specification (in its limited form) had to rely on intensive processes of developing the formal organizational arrangements further and on informal ways of communication.

The case study about REGKLAM raises the important question under which conditions it is reasonable to expect that large project networks will make significant contributions to social capacity building for natural hazards. Large project networks may trigger difficult questions about the governance of the project network governance form ("metagovernance", Sørensen and Torfing, 2009). Large, state-funded project networks could and perhaps should be accompanied by high expectations with regard to the network output and with regard to how these networks are organized through (1) metagovernance, (2) a specific governance form and (3) effective network management strategies (Klijn, 2008).

\subsection{Comparison of the case studies}

The case studies about KLIMAfit and REGKLAM show some empirical evidence based on a tentative and selective description and explanation of the two cases. Table 3 uses the conceptual categories developed in previous sections for giving an overview of the results of the two studies. 
Table 3. Comparing KLIMAfit and REGKLAM from a network management perspective (state of work: November 2013 ).

\begin{tabular}{ll}
\hline KLIMAfit project network (July 2009-April 2013) & REGKLAM project network (July 2008-December 2013) \\
\hline $\begin{array}{l}\text { Goal directedness through an intensive process of goal specifi- } \\
\text { cation, formalization, and implementation }\end{array}$ & $\begin{array}{l}\text { Limited goal directedness through an intensive process of for- } \\
\text { malization and implementation }\end{array}$ \\
$\begin{array}{l}\text { Small project network due partly to the limited grant by the Fed- } \\
\text { eral Government }\end{array}$ & $\begin{array}{l}\text { Large project network due partly to the grant by the Federal } \\
\text { Government }\end{array}$ \\
$\begin{array}{l}\text { Modest degree of heterogeneity (small network of planners and } \\
\text { planning researchers) }\end{array}$ & $\begin{array}{l}\text { High degree of heterogeneity (but only very limited inclusion of } \\
\text { politicians...) }\end{array}$ \\
$\begin{array}{l}\text { Lead organization network (regional planning office as leading } \\
\text { network actor) }\end{array}$ & $\begin{array}{l}\text { Hybrid governance form and multiple identities (network of re- } \\
\text { searchers and governance network) }\end{array}$
\end{tabular}

\section{Conclusions}

Two conclusions are drawn from the attempt in this paper to conceptualize goal-oriented networks and to interpret the findings from two case studies about social capacity building for natural hazards in the Dresden region. The first conclusion focuses on research about capacity building. The second conclusion makes a suggestion how practitioners can use the findings of this paper in networking for social capacity building for natural hazards.

Firstly, effective networks that contribute to social capacity building for natural hazards at regional level are characterized by intensive collective processes of interpreting the network goal. Goal statements will often refer to "tangible" network outputs (e.g., documents to prepare formal planning, a program document) and only indirectly and perhaps vaguely to social capacity building for natural hazards as a transformative goal (Healey, 2007) across all levels of networking (see Table 2). This conclusion should hold for small and large networks with modest or high heterogeneity and for networks with strong leadership or a more hybrid form of network governance.

This is not to say that all goal-oriented networks in society need intensive processes of goal specification (Raab and Kenis, 2009). However, the two case studies about networks in the Dresden region suggest that social capacity building for natural hazards at the regional level requires intensive "sensemaking" (Weick, 1995) of the network goal, in particular if effectiveness is an important criterion of network evaluation (Provan and Sydow, 2008). Sensemaking of the network goal is especially important in the context of capacity building for natural hazards, if the network actors face a situation in which they need to make sense of high quantities of information in diverse knowledge contexts that are due to network heterogeneity. Making sense of a network goal can be an important way to avoid information overload (Sutcliffe and Weick, 2008).

Hence, the paper confirms the proposition of Vlaar et al. (2006) and Huxham and Vangen (2005) that network management through mechanisms of incentives, coordination, control, and evaluation needs to be complemented by at least equally intensive efforts to make sense of the purpose of working together. Organizing and strategizing are both important investments in network development for building capacities for natural hazards (Denis et al., 2009, p. 241-245). What will vary with regard to structural network features are the specific patterns of making sense of the network goal based on case-specific formal arrangements and informal ways of communication (Ring and Van de Ven, 1994; Weick, 1995; Klijn, 2008). With regard to such network variety, it is important to note that this paper is based on only two intensive case studies. It is worthwhile considering further cases of inter-organizational networks that are relevant for social capacity building for natural hazards. This could be accomplished through more ambitious comparative case study designs (e.g., Van de Ven, 2007; Yin, 2009) or network surveys (see Nooteboom, 2008). Thereby it would be interesting to compare state-funded regional initiatives of social capacity building for natural hazards (e.g., KLIMAfit, REGKLAM) with initiatives that develop under different resource conditions (e.g., "bottom-up initiatives to deal with natural hazards in the context of climate change without support by Federal Government").

With regard to the limited empirical basis of this paper, recommendations to practitioners run the risk of being overgeneralizations. This again points to the need for more comparative case studies and network surveys. However, secondly, it still seems reasonable to conclude that network practitioners could benefit from considering more intensively the challenge of creating goal directedness in goal-oriented networks. Klijn (2008, p. 133) gives an overview of network management strategies. In one dimension, there is a distinction between strategies for managing interactions within a given network on the one hand and strategies for managing and changing the network structure on the other. In a second dimension, there is a differentiation between strategies of activation of actors and resources, goal-achieving strategies, and organizational arrangements. In this approach, the challenge of creating goal directedness as a precondition for adopting goal-achieving strategies is not sufficiently 
considered. Goal-orientation of networks is easily confused with goal directedness (see Table 1). We suggest that network practitioners should acknowledge the challenge of creating goal directedness in networks as a management task on its own. This task will encompass a spectrum of specific management activities, for instance, using the process of formalization to establish a network as a way to understand more thoroughly the network partners and how they interpret the network goal (Vlaar et al., 2006), comparing initial goal statements with interim results to discover interesting deviations (Weick, 1995; Ansell and Gash, 2007), and interpreting network outputs against the background of the initial network goal statement (Provan and Sydow, 2008) to build social capacities for natural hazards (Kuhlicke et al., 2012).

Acknowledgements. The paper is based on research about two goal-oriented networks in the Dresden region: firstly, there was the project network "Raumentwicklungsstrategie zum Klimawandel durch Untersuchungen zur Wirksamkeit des Regionalplanes und Integration informeller Instrumente (KLIMAfit)" (www.rpv-elbtalosterz.de). The "Bundesministerium für Verkehr, Bau und Stadtentwicklung (BMVBS)" and the "Bundesinstitut für Bau-, Stadt- und Raumforschung (BBSR)" supported KLIMAfit within the "Modellvorhaben der Raumordnung (MORO): Raumentwicklungsstrategien zum Klimawandel (KLIMA MORO)", (www.klimamoro.de). In the first phase of KLIMA MORO, eight regions participated, while seven regions were supported in the second phase. Secondly, there is project network "Entwicklung und Erprobung eines Integrierten Regionalen Klimaanpassungsprogramms für die Modellregion Dresden (REGKLAM)" (www.regklam.de). The REGKLAM project network is financed by the "Bundesministerium für Bildung und Forschung (BMBF)" within the program of KLIMZUG (www.klimzug.de). The KLIMZUG program focuses on adaptation to the impacts of climate change in cities and regions. The BMBF supports seven regions in Germany within this program.

Edited by: C. Kuhlicke

Reviewed by: three anonymous referees

\section{References}

Aldrich, H. E. and Ruef, M.: Organizations Evolving, London, Thousand Oaks, 2006.

Ansell, Ch. and Gash, A.: Collaborative Governance in Theory and Practice, J. Public Admin. Res. Theor., 18, 543-571, 2007.

Benz, A. and Fuerst, D.: Policy Learning in Regional Networks, Euro. Urban Reg. Stud., 9, 21-35, 2002.

Borgatti, St. P. and Foster, P. C.: The Network Paradigm in Organizational Research: A Review and Typology, J. Manage., 29, 991-1013, 2003.

Borgatti, St. P. and Halgin D. S.: On Network Theory, Organization Sci., 22, 1168-1181, 2011.

Carlsson, L. and Sandström, A.: Network Governance and the Commons, Int. J. Commons, 2, 33-54, 2008.

Comfort, L. K., Boin, A., and Demchak, C. C. (Eds.): Designing Resilience. Preparing for Extreme Events, Pittsburgh, 2010.
Denis, J.-L., Lamothe, L., Langley, A., Breton, M., Gervais, J., Trottier, L.-H., Contandriopoulos, D., and Dubois, C.-A.: The Reciprocal Dynamics of Organizing and Sense-making in the Implementation of Major Public-Sector Reforms, Canadian Public Administration, 52, 225-248, 2009.

Diller, Ch.: Zwischen Netzwerk und Institution, Eine Bilanz regionaler Kooperationen in Deutschland, Opladen, 2002.

Dougherty, D.: Grounded Theory Research Methods, edited by: Baum, J. C. Blackwell Companion to Organizations, Malden, 849-866, 2002.

Eden, C. and Huxham, Ch.: The Negotiation of Purpose in Multiorganizational Collaborative Groups, J. Manage. Stud., 38, $373-$ 391, 2001.

Geddes, M.: Inter-organizational Relationships in Local and Regional Development Partnerships, in: The Oxford Handbook of Inter-organizational Relations, edited by: Cropper, St., Ebers, M., Huxham, Ch., Ring, P. S., Oxford, 203-230, 2008.

Greiving, St.: Informelle raumplanerische Ansätze zur Anpassung an den Klimawandel, SIR-Mitteilungen und Berichte, 34, 27-37, 2010.

Gulati, R., Dialdin, D. A., and Wang, L.: Organizational Networks, in: Blackwell Companion to Organizations, edited by: Baum, J. C., Malden, 281-303, 2002.

Healey, P.: Urban Complexities and Spatial Strategies, Towards a Relational Planning for our Times, Milton Park, 2007.

Healey, P.: In Search of the "Strategic" in Spatial Strategy Making, Planning Theor. Practice, 10, 439-457, 2009.

Hutter, G.: Klimaanpassung im ländlichen Raum, Zielgerichtete Netzwerke am Beispiel KLIMAfit, RaumPlanung, 160, 30-34, 2012.

Hutter, G. and Bohnefeld, J.: Vielfalt und Methode - Über den Umgang mit spannungsreichen Anforderungen beim Formulieren eines Klimaanpassungsprogramms am Beispiel REGKLAM, in: Partizipation und Klimawandel - Ansprüche, Konzepte und Umsetzung, edited by: Knierim, A., Baasch, St., and Gottschick, M., München, 151-172, 2013.

Hutter, G. and Wiechmann, Th. (Eds.): Strategische Planung, Zur Rolle der Planung in der Strategieentwicklung für Städte und Regionen, Berlin, 2010.

Hutter, G., Bohnefeld, J., and Olfert, A.: Zielgerichtete Netzwerke in Regionen und landespolitische Handlungsansätze - am Beispiel von REGKLAM, in: Governance in der Klimaanpassung - Strukturen, Prozesse, Interaktionen, edited by: Cormont, P. and Frank, S., Dortmund, 74-89, 2011.

Huxham, Ch. and Vangen, S.: Managing to Collaborate, The Theory and Practice of Collaborative Advantage, Milton Park, 2005.

Jones, C., Hesterly, W. S., and Borgatti, St. P.: A General Theory of Network Governance: Exchange Conditions and Social Mechanisms, Aca. Manage. Rev., 22, 911-945, 1997.

Jones, C. and Liechtenstein, B. B.: Temporary Inter-organizational Projects. How Temporal and Social Embeddedness Enhance Coordination and Manage Uncertainty, in: The Oxford Handbook of Inter-organizational Relations, edited by: Cropper, St., Ebers, M., Huxham, Ch., and Ring, P. S., Oxford, 231-255, 2008.

Kilduff, M. and Tsai, W.: Social Networks and Organizations, London, 2003.

Klemme, M.: Akteure der lokalen Klimapolitik im Spannungsfeld von Persistenzen und Eigenlogiken, in: Anpassung an den Klimawandel - regional umsetzen! Ansätze zur Climate Adaption 
Governance unter der Lupe, edited by: Frommer, B., Buchholz, F., and Böhm, H. R., München, 121-138, 2011.

Klijn, E.-H.: Policy and Implementation Networks: Managing Complex Interactions, in: The Oxford Handbook of Interorganizational Relations, edited by: Cropper, St., Ebers, M., Huxham, Ch., and Ring, P. S., Oxford, 118-146, 2008.

Knight, L.: Network Learning: Exploring Learning by Interorganizational Networks, Human Relations, 55, 427-454, 2002.

Kuhlicke, Ch., Steinfuehrer, A., Begg, Ch., Bianchizza, Ch., Bruendl, M., Buchecker, M., De Marchi, B., Di Masso Tarditti, M., Hoeppner, C., Komac, B., Lemkowe, L., Luther, J., McCarthy, S., Pellizzoni, L., Renn, O., Scolobig, A., Supramaniam, M., Tapsell, S., Wachinger, G., Walker, G., Whittle, R., Zorn, M., and Faulkner, H.: Perspectives on social capacity building for natural hazards: outlining an emerging field of research and practice in Europe, Environ. Sci. Policy, 14, 804-814, 2011.

Kuhlicke, Ch., Steinführer, A., Begg, Ch., and Luther, J.: Toward More Resilient Societies in the Field of Natural Hazards: CapHaz-Nets Lessons Learnt, Leipzig/Braunschweig, 2012.

McGrath, J. E. and Rotchford, N. L.: Time and Behavior in Organizations, in: Research in Organizational Behavior, 5, 57-101, 1983.

Meyer, J. W. and Rowan, B.: Institutionalized Organizations: Formal Structure as Myth and Ceremony, Am. J. Sociol., 83, 340363, 1977.

Nooteboom, B.: Learning and Innovation in Inter-organizational Relationships, in: The Oxford Handbook of Inter-organizational Relations, edited by: e Cropper, St., Ebers, M., Huxham, Ch., and Ring, P. S., Oxford, 607-634, 2008.

Orlikowski, W. J. and Yates, J.: It's About Time: Temporal Structuring in Organizations, Organization Science, 13, 684-700, 2002.

Pelling, M.: Adaptation to Climate Change. From Resilience to Transformation, London/New York, 2011.

Powell, W. W.: Neither Market Nor Hierarchy: Network Forms of Organization, Research on Organizational Behavior, 12, 295336, 1990.

Powell, W. W. and Grodal, S.: Networks of Innovators, in: The Oxford Handbook of Innovation, edited by: Fagerberg, J., Mowery, D. C., and Nelson, R. R., Oxford, 56-85, 2005.

Provan, K. G. and Kenis, P.: Modes of Network Governance: Structure, Management, and Effectiveness, J. Public Admin. Res. Theor., 18, 229-252, 2007.

Provan, K. G. and Sydow, J.: Evaluating Inter-organizational Relationships, in: The Oxford Handbook of Inter-organizational Relations, edited by: Cropper, St., Ebers, M., Huxham, Ch., and Ring, P. S., Oxford, 691-716, 2008.
Raab, J. and Kenis, P.: Heading Toward a Society of Networks: Empirical Developments and Theoretical Challenges, J. Manage. Inquiry, 18, 198-210, 2009.

Ring, P. S. and Van de Ven, A.: Developmental Processes of Cooperative Interorganizational Relationships, Academy Manage. Rev., 19, 90-118, 1994.

Roessler, St., Hutter, G., and Mueller, B.: Entwicklung und Erprobung eines Integrierten Regionalen Klimaanpassungsprogramms für die Modellregion Dresden, UVP-Report, 27, 125130, 2013.

Sandström, A. and Carlsson, L.: The Performance of Policy Networks: The Relation between Network Structure and Network Performance, Policy Studies J., 36, 497-524, 2008.

Scott, W. R.: Institutions and Organizations, Ideas and Interests, Los Angeles, 2008.

Sørensen, E. and Torfing, J.: The Democratice Anchorage of Governance Networks, Scandinavian Politic. Stud., 28, 195-218, 2005.

Sørensen, E. and Torfing, J.: Theories of Democratic Network Governance, Basingstoke, 2007.

Sørensen, E. and Torfing, J.: Making Governance Networks Effective and Democratic Through Metagovernance, Public Administration, 87, 234-258, 2009.

Sutcliffe, K. M. and Weick, K. E.: Information Overload Revisited, in: The Oxford Handbook of Organizational Decision Making, edited by: Hodgkinson, G. P. and Starbuck, W. H., Oxford, 5675, 2008.

Van de Ven, A. H.: Engaged Scholarship, A Guide for Organizational and Social Research, Oxford, 2007.

Van Wijk, R., Van den Bosch, F. A. J., and Volberda, H. W.: Knowledge and Networks, The Blackwell Handbook of Organizational Learning and Knowledge Management, edited by: EasterbySmith, M. and Lyles, M. A., Malden/Oxford, 428-453, 2003.

Vlaar, P. W. L., Van den Bosch, F. A. J., and Volberda, H. W.: Coping with Problems of Understanding in Interorganizational Relationships: Using Formalization as a Means to Make Sense, Organization Studies, 27, 1617-1638, 2006.

Weick, K. E.: Sensemaking in Organizations, London, 1995.

Weick, K. E. and Quinn, R. E.: Organizational Change and Development, Ann. Rev. Psychol., 50, 361-386, 1999.

Wiechmann, Th.: Planung und Adaptation, Strategieentwicklung in Organisationen, Regionen und Netzwerken, Dortmund, 2008.

Windeler, A. and Sydow, J.: Project Networks and Changing Industry Practices - Collaborative Content Production in the German Television Industry, Organization Studies, 22, 1035-1060, 2001.

Yin, R. K.: Case Study Research, Design and Methods, Thousand Oaks, 2009. 